\title{
IMMATURE TERATOMA OF OVARY- A CASE REPORT
}

S. S. Devarmani, Meenakshi S. Devarmani, Rajshekhar S. J.

1. Professor, Department of Pathology, M. R. Medical College, Gulbarga, Karnataka, India

2. Professor, Department of Obstetrics \& Gynaecology, M. R. Medical College, Gulbarga, Karnataka, India

3. Professor, Department of Pathology, M. R. Medical College, Gulbarga, Karnataka, India

\section{CORRESPONDING AUTHOR}

\section{Dr. S. S. Devarmani}

Professor, Department of Pathology,

M. R. Medical College, Sedam Road,

Gulbarga, Karnataka, India

E-mail: drssdevarmani@gmail.com

Ph: 00919448046660

\begin{abstract}
BACKGROUND: Immature teratoma is the currently preferred term for the malignant ovarian teratoma composed of a mixture of embryonal and adult tissues derived from all three germ layers, regardless of its gross appearance. AIM: to distinct mature and immature teratoma when dealing with ovarian germ cell tumors. CASE SUMMARY: a 30 year female presented with intra abdominal mass and ascitis. Grossly, variable size nodule and cystic areas are seen. Microscopically, carcinoid like lesion, thyroid tissue immature neural tissue and glandular tissue noted. Diagnosis of immature teratoma grade 3 was made. DISCUSSION: immature teratoma of ovary accounts for $10-20 \%$ of all ovarian tumors and is considered second most common germ cell tumor following mature teratoma. It is usually seen in children and adolescents. CONCLUSION: A thorough search for immature elements in a teratoma is necessary for proper grading, management and assessing prognosis of cases with immature teratoma.
\end{abstract}

KEY WORDS: immature teratoma, ovary, carcinoids

INTRODUCTION: An immature-teratoma is a tumor arising from totipotent cells of gonads or extragonadal sites containing elements differentiating into two or more germ cell types with variable amount of immature tissue. Incidence is about 3\% of teratomas, $1 \%$ of all ovarian cancers and $20 \%$ of malignant germ cell Tumors. ${ }^{1}$ According to WHO, Immature teratoma is defined as a teratoma containing a variable amount of immature embryonal type neuroectodermal tissue. It is rapidly growing malignant tumor that occur in children and young adults. They are unilateral and typically have solid and cystic components.

CASE SUMMARY: A 30year female presented with mass per abdomen-4 months. USG revealed right sided cystic-ovarian mass measuring $15 \times 10 \mathrm{cms}$ with mild ascitis. Exploratory Laparotomy was done with hysterectomy and right side salpingo-oophorectomy.

Gross: A large ovarian mass $(20 \times 15 \times 10 \mathrm{cms})$ with attached fallopian tube. External surface smooth, shiny and C/S was solid and cystic with multiple variable sized cysts and nodules of solid area with hemorrhage and necrosis.

MICROSCOPY: Ovarian mass reveals predominantly carcinoids-like lesion, thyroid tissue, glandular tissue, immature neural tissue and cystic spaces lined by low columnar cells with prominent stratification. There are small foci resembling immature cartilage, hair follicle and 
peripheral nervous tissue, endometrial tissue and immature tissue which cannot be categorized. Overall features are consistent with diagnosis of Immature Teratoma-Grade 3. Uterus and Cervix were unremarkable.

DISCUSSION: Immature ovarian teratoma usually affects younger age and most are in Stage I at the time of diagnosis. Carcinoid is seen rarely and review of literature revealed a reported case in a growing teratoma syndrome. ${ }^{2}$

Grading is done according to Norris classification and overall survival is $30 \%$ for grade III tumors and hence adequate sampling with 1 block/cm is necessary. ${ }^{3}$

Immature teratomas differ from mature cystic teratomas in that they demonstrate clinically malignant behavior, are much less common, affect a younger age group and are histologically distinguished by the presence of immature or embryonic tissues. ${ }^{4}$

Thus, the distinction between immature and mature teratoma is based on identification of foci of immature embryonal tissue. However presence of microscopic foci of immature tissue in an otherwise typical dermoid cyst should not lead to diagnosis of immature teratoma. ${ }^{4}$

Tumor grading is based on the amount of immature tissue present. Recently, the amount of yolk sac tumor within immature teratomas has been recognized as both the source of alphafetoprotein in affected patients and the major predictor of stage, grade, and rate of recurrence. 5 The treatment of immature teratoma consists of surgery plus multidrug chemotherapy. Sometimes, only mature tissue is found in metastatic sites following chemotherapy, a sign of excellent prognosis. The prognosis depends a great deal on the nature and amount of the immature component. 6

CONCLUSION: Morphological spectrum of immature teratoma of ovary is varied, complex and offers diagnostic challenge. Literature suggests mere presence of immature mesenchyme is not sufficient. A thorough search for immature elements in a teratoma is necessary for proper grading, management and assessing prognosis of cases with immature teratoma.

\section{REFERENCES:}

1. Fattaneh AT, Devilee P. Pathology and Genetics. Tumors of the breast and female genital organs; In. WHO Classification of Tumors. Fattaneh AT, Devilee P. IARC Press; Lyon; 2003.

2. Bojana Djordjevic et al. Growing Teratoma Syndrome of the Ovary: Review of Literature and first Report of a Carcinoid Tumor Arising in a Growing Teratoma of the Ovary; Am J Surg Path. 2007; 31; 12 (1); 1913-1918.

3. Donny JK, Pfeiffer JD, Huettner PC. Ovary; In. The Washington Manual of Surgical Pathology; Editors: Humphrey PA; Dehner LP, Pfeiffer JD; Publication: Wolter Kluwer (India) Ltd; $1^{\text {st }}$ edition; 2009; 399-413.

4. Eric K. Outwater, Evan Siegelman, Jeniffer L. Hunt. Ovarian teratomas: tumor types and imaging characteristics; RadioGraphics 2001; 21:475-490.

5. KK Deodhar et al. Immature teratoma of ovary: A clinicopathological study of 28 cases; Ind J Pathol Microbiol 2011;54(4):730-735.

6. O'Connor DM, Norris HJ: The influence of grade on the outcome of stage I ovarian immature (malignant) teratomas: the reproducibility of grading. Int J Gynecol Pathol 1994;13:283-289. 


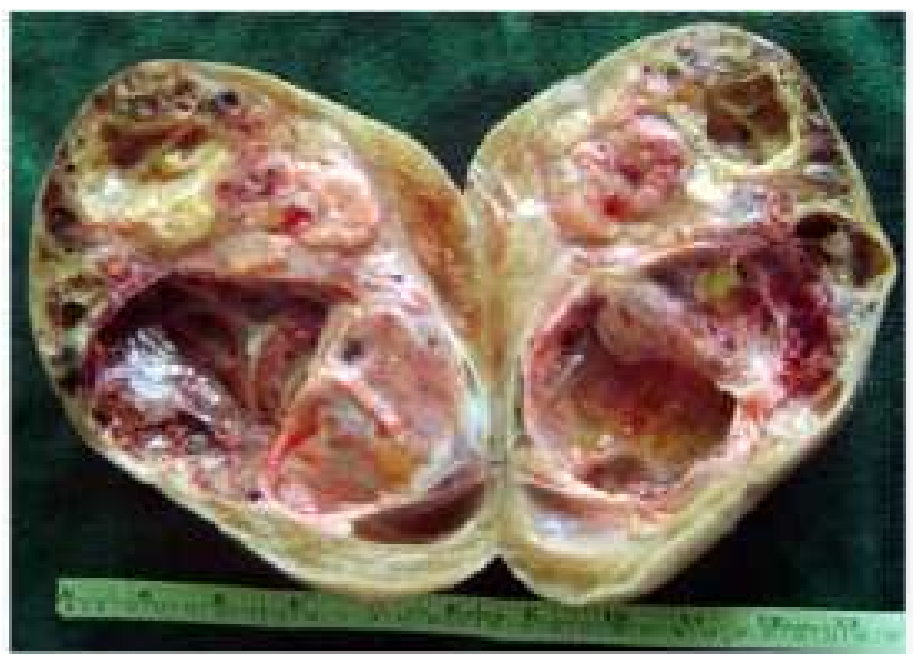

Fig 1: Multiple variable sized cysts and nodules of solid area with hemorrhage and necrosis.

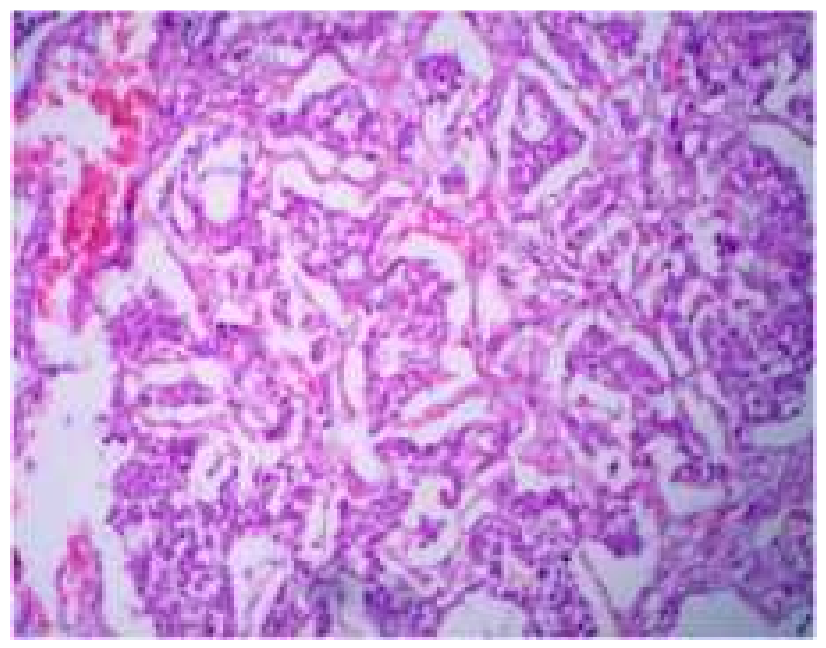

Fig 2: Predominantly carcinoid like lesion. (H\&E X 100) 


\section{CASE REPORT}

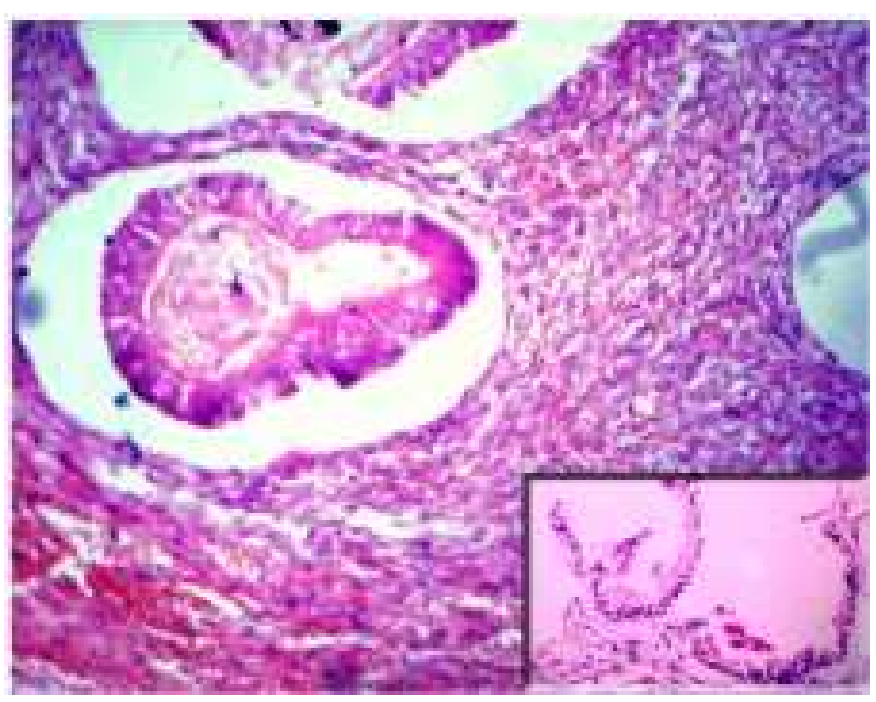

Fig 3: Foci of endometrial tissue and immature nervous tissue with cyst lined by low columnar epithelium (inset). (H\&E X 400) 